\title{
2017 - 2018 Winter Weather Surveillance in Louisiana
}

\section{Dayaamayi Kurimella, Gillian Richardson}

Louisiana Department of Health, New Orleans, Louisiana, United States

\section{Objective}

The Louisiana Early Event Detection System (LEEDS), Louisiana's syndromic surveillance system, was used to monitor uncharacteristically low temperatures during the 2017-2018 winter season and determine the impact of these temperatures on the number of weather related personal injuries in emergency departments throughout Louisiana.

\section{Introduction}

The Infectious Disease Epidemiology Section (IDEpi) in the Louisiana Office of Public Health (OPH) has several applications for syndromic surveillance including situational awareness during unusual and/or high profile events, such as the uncharacteristic winter weather Louisiana experienced during the 2017-2018 winter season. December $8^{\text {th }}, 2017$ saw freezing temperatures with some parts of the state experiencing snow, and January $16-18,2018$ saw record breaking freezing temperatures throughout the state. Both weather events led to many state office, school and business closures. The freezing temperatures from January $16^{\text {th }}-18^{\text {th }}$ led to office closures that lasted longer than the freezing temperatures due to the infrastructure damage the freezing temperatures caused. For example, Orleans parish experienced low water pressure throughout its water systems due to broken pipes following the freeze, leading to boil water advisories.

Many people throughout Louisiana had broken pipes at their homes, resulting in flooding and further contributing to low water pressure in some areas. IDEpi used syndromic surveillance to monitor the impacts of the severe winter weather and its aftermath on weather related personal injuries throughout the state.

\section{Methods}

LEEDS was queried to obtain the number of cold weather related emergency department visits. This was done by querying for records that mentioned "cold exposure," "fell on ice," "freeze," "hypothermia," "ice," "slipped on ice," or "snow" in the chief complaint or admit reason. Records were excluded if they mentioned "antifreeze," "device," "jaundice," "lice," "notice," "office," "orifice," "police," "practice," "septicemia," "twice," or "voice" in the chief complaint or admit reason. A record review was done to determine if the returned visits were in fact cold weather related, and the number of visits were grouped by triage date. The daily cold weather related ED visit counts were plotted against weather data taken from ESSENCE, the National Syndromic Surveillance Program's syndromic surveillance application. The data obtained from ESSENCE was used to calculate the daily average minimum temperature throughout Louisiana from December 1, 2017 through February $29,2018$. This was done by selecting all of the fourteen Louisiana weather stations in ESSENCE and calculating the daily average minimum temperature across all stations. The number of cold weather related ED visits were then plotted against the daily minimum temperature in Louisiana. The initial active surveillance took place during the extreme cold weather that occurred from January 15, 2018 - January 20, 2018. Data starting on December 1, 2017 was pulled to provide a baseline. Additional data through February 28, 2018 was pulled retrospectively to analyze the overall trend of cold weather related ED visits throughout winter season.

\section{Results}

Cold weather related ED visits and daily average minimum temperatures were analyzed for the time period of December 1 , 2017 to February 28, 2018. The average number of cold weather ED visits for this time period was 1.8 visits with a standard deviation of $+/-4.4$ visits, and the average minimum temperature was

$40.9^{\circ} \mathrm{F}$. The number of cold weather related ED visits went above 6.1 visits on the following occasions: December $9^{\text {th }}$ had 7 visits and an average minimum temperature of $25.9{ }^{\circ} \mathrm{F}$ and January $17^{\text {th }}-18^{\text {th }}$ had 37 and 18 visits, respectively, with respective average minimum temperatures of $12.5^{\circ} \mathrm{F}$ and $16.1^{\circ} \mathrm{F}$. The 2017 - 2018 Winter Weather Surveillance in Louisiana graph also reflects these results. Of the cold weather related ED visits that took place on either December $9^{\text {th }}$ or January $17^{\text {th }}-18^{\text {th }}, 81 \%$ indicated an ice or snow related personal injury, $14 \%$ indicated hypothermia, and $5 \%$ indicated cold exposure. 


\section{Conclusions}

The three coldest days, January $16^{\text {th }}-18^{\text {th }}$, corresponded with the largest spikes in cold weather related ED visits. The spike in visits on December 9, 2017 did not correspond to very low temperatures, but areas of Louisiana did experience snowfall on December $8^{\text {th }}$, which led to ice formation. A record review of all visits that fit the inclusion criteria of a cold weather related ED visit showed that many of the visits that took place from January $19^{\text {th }}-21^{\text {st }}$ were also personal injuries that had either just taken place from slipping on ice or had occurred several days prior and remained unresolved. Ultimately, syndromic surveillance was instrumental in maintaining situational awareness during the uncharacteristic winter weather experienced in Louisiana. The results of this winter weather surveillance were published in the Louisiana Morbidity Report. IDEpi will continue to use syndromic surveillance during periods of uncharacteristic winter weather to maintain situational awareness, which may be used in public safety messaging to reduce the number of cold weather related personal injuries in the population that is not accustomed to such conditions.

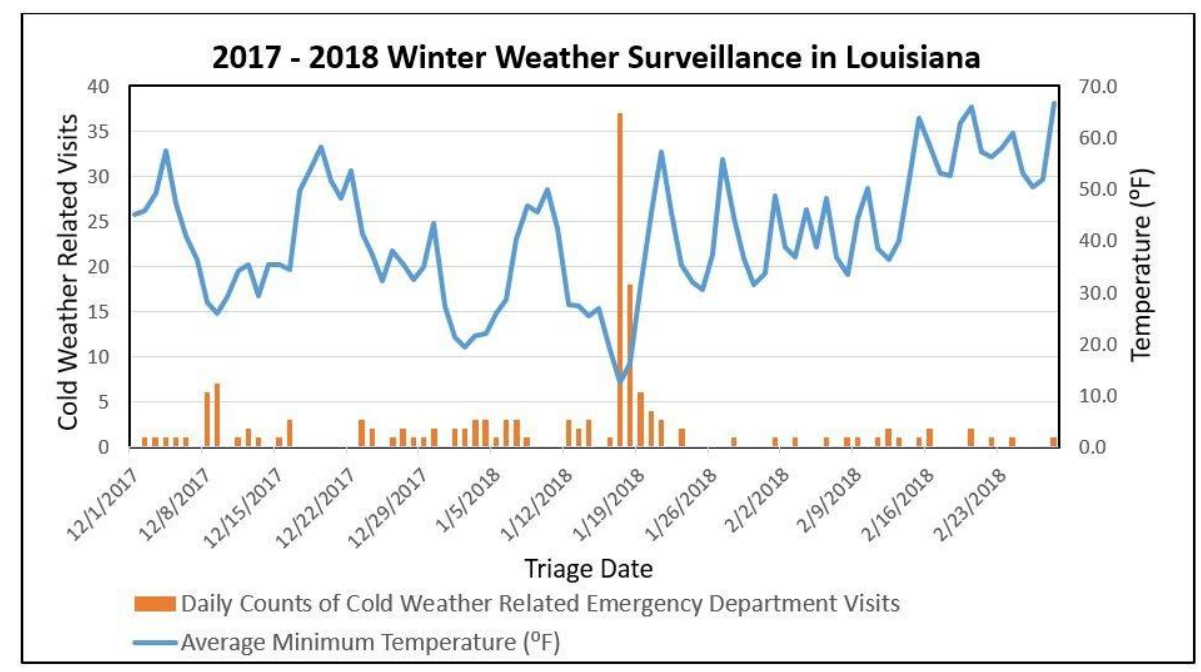

SDS Annual Conference Proceedings 2019. This is an Open Access article distributed under the terms of the Creative Commons AttributionNoncommercial 3.0 Unported License (http://creativecommons.org/licenses/by-nc/3.0/), permitting all non-commercial use, distribution, and reproduction in any medium, provided the original work is properly cited. 